\title{
Public Health in Political Dilemma - A Case for Covid-19 Control
}

SK Singh ${ }^{1}$, VK Srivastava ${ }^{2}$

${ }^{1}$ Professor, Department of Community Medicine \& Public Health, King George's Medical University, Uttar Pradesh; ${ }^{2}$ Former Professor, Department of Community Medicine, KGMU, Lucknow \& Principal, Prasad Institute of Medical Sciences, Lucknow, Uttar Pradesh

\begin{tabular}{|c|c|c|c|c|c|c|c|c|}
\hline Abstract & Introduction & Methodology & Results & Conclusion & References & Citation & \multicolumn{2}{|c|}{ Tables / Figures } \\
\hline \multicolumn{9}{|c|}{ Corresponding Author } \\
\hline \multicolumn{8}{|c|}{$\begin{array}{l}\text { Dr SK Singh, Professor, Department of Community Medicine \& Public Health, King George's Medical } \\
\text { University, Uttar Pradesh, } 226003 \\
\text { E Mail ID: shivmymail0522@gmail.com }\end{array}$} & 回语四 \\
\hline
\end{tabular}

\section{Citation}

Singh SK, Srivastava VK. Public Health in Political Dilemma - A Case for Covid-19 Control. Indian J Community Health. 2020; 32(2):311 - 312 .

Source of Funding: Nil Conflict of Interest: None declared

\section{Article Cycle}

Received: 12/04/2020; Revision: 20/05/2020; Accepted: 26/06/2020; Published: 30/06/2020

This work is licensed under a Creative Commons Attribution 4.0 International License.

COVID 19 has been declared a Public Health Emergency of International Concern by the WHO (1). The management of COVID 19 pandemic by Govt. of India has been applauded by the WHO for its timely and strict actions. No doubt we have borrowed time from the lockdown but it could have been utilized in a much better way to control. The epidemiological opinion is that the harshest lockdown was acceptable but its extension was not required as we have not been able to sustain the benefits of lockdown gained in the beginning. The gain of lockdown could have been better had it been coupled with meticulous contact tracing and containment measures during the early period of pandemic. A subsequent failure to ensure all these together resulted in spread of virus everywhere in spite of lockdown. It has also given a false feeling to the public that lockdown will prevent infection.

Every disease is unique in terms of its transmission dynamics thereby requiring a specific control strategy based on scientific rationale and best available evidences. An epidemiologist is an expert specifically trained to understand these intricacies. He then communicates it appropriately to the decision-making authorities for the most feasible and practical action to control the disease in the population. Unfortunately, both our public as well as politicians remain unaware of the actual role played by these Epidemiologists/Public Health Specialists. Consequently, our lockdown was more focused on law and order rather than Public Health. There are different versions and strategies of a lockdown to be used. Important was the approach wherever it was used as a public health measure such as in countries like Vietnam and Thailand where they have done well.
A joint statement on COVID-19 was released on 11th April, 2020 by the Indian Public Health Association and Indian Association of Preventive \& Social Medicine, representing a very wide community of public health academician, practitioners and researchers in India. A 10-point action plan for control of pandemic was suggested which offered that after the first phase of 21 days of lockdown it should be followed by cluster restrictions and containment (2). Though it might sound simple, it requires a well-trained Epidemiologist for implementation in a scientific manner. A second joint statement of Public Health Associations was again issued with 11 strategic points for Pandemic Control (3). Apart from technical advice it has stressed on formation of an inter-disciplinary panel of public health, preventive health experts and social scientists.

The epidemiologists are available in Medical Colleges and Public Health Institutes. The district level Epidemiologists are also available in limited numbers under National Health Mission who primarily handle the Integrated Disease Surveillance Programme. In many States of India, the health departments do not have a Public Health Cadre, which can handle the epidemics/pandemics. This cadre issue has been raised many times but the Govt. is yet to realize its importance. Consequently, any health programme is headed by senior level medical officer, who are non-specialist without any academic training in epidemiology or program management. The posts of epidemiologists under the National Health Mission are vacant in many districts; the main reason being meager salary. Even those who are appointed, they are just MBBS or BAMS/BHMS+MPH without any essential requirement of experience. No support for field visit in terms of man, 

money and material. They are simply given a seat in the district health office and main focus is on IDSP reporting. This also creates a gap which is being filled by health graduates after doing short courses in public health or epidemiology. The quality is never in question when there is shortage of quantity. This clearly reflects the negligence given to Public Health in our country at both policy and implementation level.

The foundation of public health is laid down in a Medical College both for undergraduates and postgraduates by the Department of Community Medicine. In many districts, the need of epidemiologist/public health specialist, is met by this department and usually utilized by the government for programme evaluation or epidemic control. Out of the 700 odd districts, there are over 550 Medical Colleges in India and this could cover at least $70 \%$ of the districts. The departments of Community Medicine of Medical Colleges have the resources and expertise to deal with epidemics/pandemics of diseases like COVID-19. The surveillance data being collected at the district level could be analyzed to generate evidence for decision making and further course of action. An experienced faculty member from this department can easily be incorporated as a member of the District Health Society, which is responsible for all public health activities in a district. The districts not yet having a medical college can be attached to the nearby Medical College as per the availability.

There is enough evidence in the history that countries who relied on opinion of epidemiologist and surveillance data have successfully overcome Pandemics. But the situation is questionable when experts of other streams are working at forefront in this crisis. Even the National Centre for Disease Control (NCDC) is not involved and data is not being disclosed. Based on a mathematical model, the Govt. of India declared that the war against Corona will take 21 days like the 18 days of Mahabharata and there would be no new COVID-19 cases from 16 May onwards. It must have been on wrong assumptions as India continues to see new infections every day, with the surging pandemic having recorded 207,615 confirmed cases and 5,815 deaths in India as of $3^{\text {rd }}$ June (4). This happens when we try to fit reality into projections. The Government claims regarding the control of Pandemic have been changing constantly as the previous one fails.

It is thus clear that the role of Public Health Specialists cannot be performed by Administrators and Police Force. Every medical doctor is trained for some specific purpose and it is a failure of the system not to utilize the services of "Public Health Specialists" for it due to various reasons. In our country traditionally only the doctors famous for their clinical acumen are considered qualified to make suggestions one every health problem and this practice needs to be changed. It is this social appraisal that discourages medical graduates to pursue Public Health as a career leading to shortage of such experts. This behaviour of society has also turned medical science from cost efficient clinical skills oriented to market driven, sophisticated lab tests and equipment oriented making health care a costly affair.

\section{References}

1. World Health Organizations. COVID-19 Public Health Emergency of International Concern (PHEIC) Global research and innovation forum. Available online at https://www.who.int/who-documentsdetail/covid-19-public-health-emergency-of-internationalconcern-(pheic)-global-research-and-innovation-forum on $28 / 05 / 2020$

2. Joint Statement on CoVID-19 Pandemic in India: Review of Current Strategy and the Way Forward. Indian J Community Health 2020, April 19; 32(2(Supp):170-174. Available from: https://www.iapsmupuk.org/journal/index.php/IJCH/article/view/ 1464

3. Second Joint Statement on COVID-19 Pandemic in India - Public Health Approach for COVID-19 Control by Joint COVID-19 Task Force Indian Public Health Association (IPHA), Indian Association of Preventive and Social Medicine (IAPSM) \& Indian Association of Epidemiologists (IAE) dated 25/05/2020

4. Vidya Krishnan. The Caravan. News Health. Epidemiologists say India's centre for disease control withheld COVID-19 data since pandemic began 12 May 2020 accessed online from https://caravanmagazine.in/health/epidemiologists-say-indiacentre-disease-control-withheld-covid-19-data-since-pandemicbegan on $21 / 05 / 2020$ 